\title{
Effects of Heating Appliances with Different Energy Efficiencies on Associations among Work Environments, Physiological Responses, and Subjective Evaluation of Workload
}

\author{
Hiroe MATSUZUKI 1, 2*, Makoto AYABE ${ }^{3,4}$, Yasuo HARUYAMA², Akihiko SEO5, \\ Shizuo KATAMOTO ${ }^{3}$, Akiyoshi ITO $^{6}$ and Takashi MUTO ${ }^{2}$

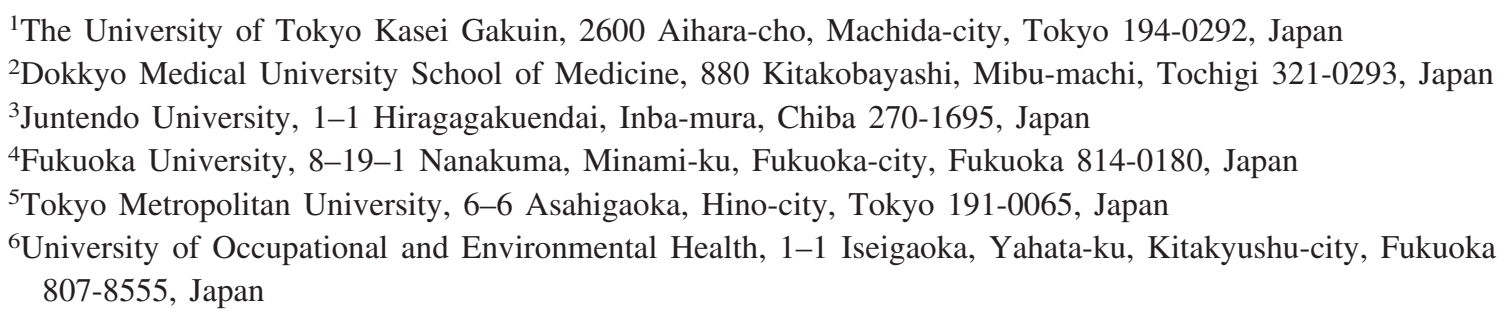

Received November 2, 2007 and accepted April 21, 2008

\begin{abstract}
To clarify the association between heat stress, physiological responses and subjective workload evaluations in kitchens using an induction heating stove (IH stove) or gas stove. The study design was an experimental trial involving 12 young men. The trial measured ambient dry-bulb temperature, globe temperature, wet-bulb globe temperature (WBGT) and relative humidity; the subjects' weight, heart rate, blood pressure, oxygen uptake, amount of activity, body temperature, subjective awareness of heat and workload before and after mock cooking for $30 \mathrm{~min}$. The IH stove insignificantly increased heat indicators in the work environment and workers showed lower oxygen uptake, skin temperature, subjective awareness of heat and workload after heat exposure. Both physiological load and subjective awareness of heat and workload were slight in kitchens using the IH stove, which provided a better work environment.
\end{abstract}

Key words: Globe temperature, IH stove, Thermal stress, Physiological response, Feeling of load

\section{Introduction}

In the food service industry, the working environment is considered to be hard due to standing at work in a hot environment, in addition to irregular working hours ${ }^{1-4)}$, and the risks of musculoskeletal disease and dermatitis are also high ${ }^{5}$.

Studies on kitchen labour have often shown a high ambient temperature in the kitchen working environment $^{6-8)}$. In recent years, environmental improvements by the introduction of electric kitchens with high energy efficiency have also been reported in Japan ${ }^{9)}$. Because the IH stove has a heating characteristic that the pot itself

*To whom correspondence should be addressed. does generate heat by electromagnetic induction, heat efficiency is high at $90 \%$, and the caloric force is strong. On the other hand, the heat efficiency of the gas stove is $20-40 \%$. There is therefore little exhaust heat with the IH stove, and the rise in kitchen temperature is slight. Concerning workload, there have been many studies on the heart rate when working in a kitchen ${ }^{8,10-13)}$, but only a few have studied physiological responses to changes in the working environment by methods including subjective evaluation of workload by workers themselves. The purpose of this study was to measure heat stress on subjects and their physiological responses, and to evaluate their association; moreover, to clarify what constitutes a comfortable kitchen environment based on the results of these measurements and subjects' feelings of heat and load. 


\section{Methods}

The subjects were 12 healthy men $(22.4 \pm 1.0 \mathrm{yr}$, $172.5 \pm 4.8 \mathrm{~cm}$ ) not acclimated to heat stress. The study design was an experimental trial. The subjects performed mock cooking once using an induction heating stove (IH stove) and once using a gas stove (total, 24 times). This study was approved by The Ethics Committee of Dokkyo Medical University and complied with the Helsinki Declaration. All subjects were fully informed of the purpose, procedures and possible risks of the study, and then gave written informed consent.

\section{Mock cooking work}

The experiment was performed in a large-scale food practical training kitchen at The University of Tokyo Kasei Gakuin (Fig. 1, $70.15 \mathrm{~m}^{2}$ in area, studding $2.6 \mathrm{~m}$ ). An exhaust hood $(1,050 \times 600$, evacuation air-capacity $1,730 \mathrm{~m}^{3} / \mathrm{h}$ ) for the upper part of the cooking stove was used in the experiment. The subjects were fasted for $8 \mathrm{~h}$ before the experiment. The total weight of clothes (underwear, trousers, socks, T-shirt, chef's coat and work gloves) was $3.1 \mathrm{~kg}$.

As shown in Figs. 2 and 3, the subjects stood with the abdomen $45 \mathrm{~cm}$ from the center of the cooking plate. The subjects stood for $10 \mathrm{~min}$ and stirred boiling water using their right hand for $20 \mathrm{~min}$. The subjects were directed not to change their position. As shown in Fig. 4, they gripped the end of a rice paddle (length, $20 \mathrm{~cm}$ ) and stirred at an angle of $180^{\circ}$ at a rate of $10 \mathrm{stirs} / \mathrm{min}$. The left upper limb was extended along the left side of the body.

As heat stress, a pan containing $1 \mathrm{~kg}$ konjak (alimentary yam paste, $2.0 \times 2.0 \times 2.0 \mathrm{~cm}$ ) and $10 \mathrm{~kg}$ water was heated, and the state $6 \mathrm{~min}$ after the water temperature reached $99^{\circ} \mathrm{C}$ was considered to be stable. In the kitchen environment, before exposure to heat stress, the ambient dry-bulb temperature in front of the stove (height from the floor, $120 \mathrm{~cm}$ ) was adjusted to $25.0 \pm 0.5^{\circ} \mathrm{C}$ using an air conditioner in each experiment. The full output of the 2 -ring gas stove $(10,000 \mathrm{kcal} / \mathrm{h})$ was used. To equalize output between the different heat sources, a rising ambient temperature test was performed, and $80 \%$ of the maximum output of the IH stove was used.

\section{Measurement}

As heating appliances, IH stoves (rated output, $5 \mathrm{~kW}$; MIR5T-N, Nichiwa Electric Corporation) and gas stoves (output, 10,000 kcal/h; 1 burner with 2 rings; Nihon Choriki Co., Ltd.) were used. The height of each stove (from the floor to the bottom of the pan) was $87 \mathrm{~cm}$, and to the top of the pan on the cooking stove was $107 \mathrm{~cm}$. Japanese pans (bottom diameter, $36 \mathrm{~cm}$; depth, $20 \mathrm{~cm}$;

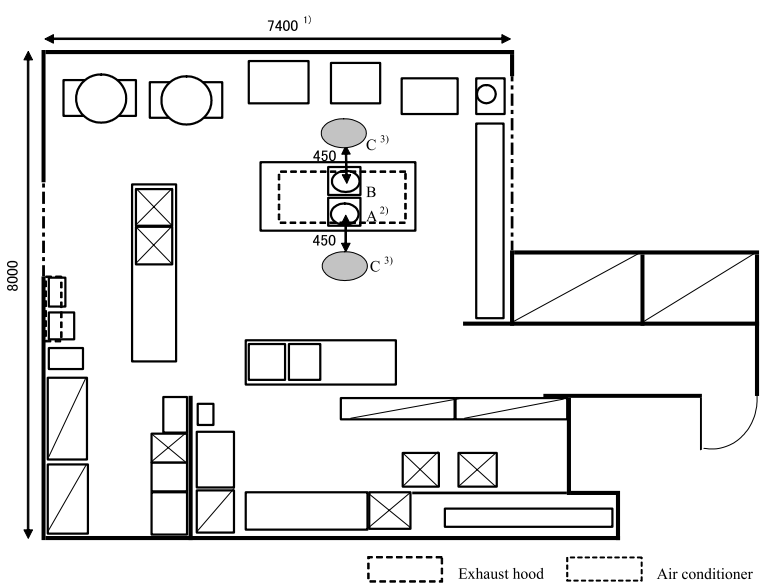

Fig. 1. A laboratory floor plan (Large scale food practical training kitchen).

1) Unit: $\mathrm{mm}$.

2) Heating appliance: A; IH stove, B; gas stove.

3) Subjects standing position: subjects stood at a distance of $45 \mathrm{~cm}$ from the center of the cooking plate.

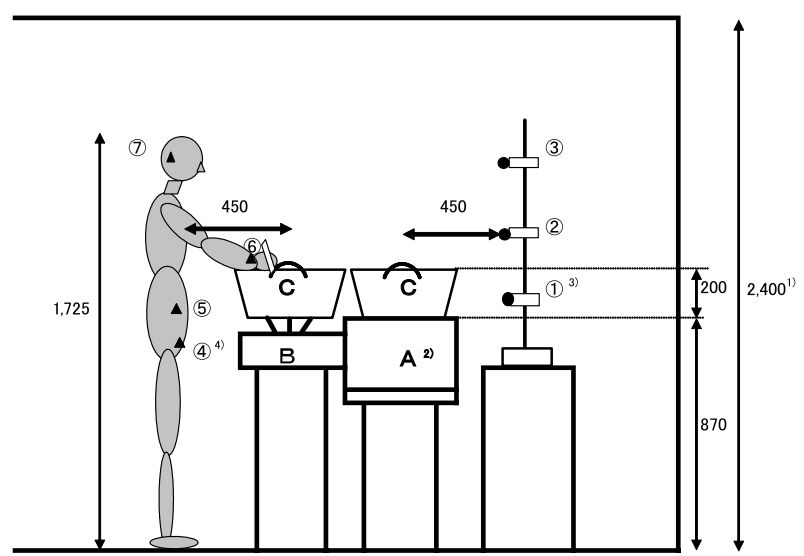

Fig. 2. An experiment elevation view.

1) Unit: $\mathrm{mm}$.

2) Heating appliance: A; IH stove, B; gas stove, C; Japanese pan that can be used for both electromagnetic appliances and gas stoves.

3) WBGT meters were set at a distance of $45 \mathrm{~cm}$ from the center of the cooking plate at height of 90 (1), 120 (2) and $150 \mathrm{~cm}$ (3) from the floor.

4) Body temperature: (4); Rectal temperature, (5); Abdominal temperature, (6); Antebrachial skin temperature, (7); External acoustic meatus temperature.

Royal Choriki Co., Ltd.) that can be used for both electromagnetic appliances and gas stoves were used. The water temperature was measured at 30 -s intervals by fixing the tip of a needle-type thermometer to measure internal temperature (Anritsu Thermo Printer AP-210 Type E, Anritsu-meter Co., Ltd.) $6 \mathrm{~cm}$ from the center of the pan bottom. The ambient dry-bulb temperature in front of the stove near the subjects was measured before and after exposure to heat stress. The ambient dry-bulb tempera- 


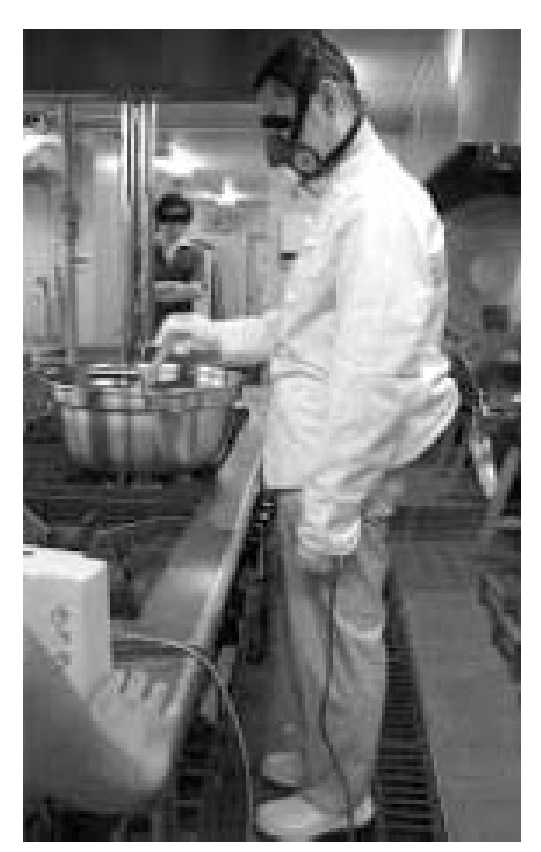

Fig. 3. Mock cooking work.

The experiment was carried out in a large-scale food practical training kitchen. The subjects stood with the abdomen $45 \mathrm{~cm}$ from the center of the cooking plate. The subjects rested for 10 min in the standing position and performed mock cooking for $20 \mathrm{~min}$.

Photo shows the experiment using the gas stove.

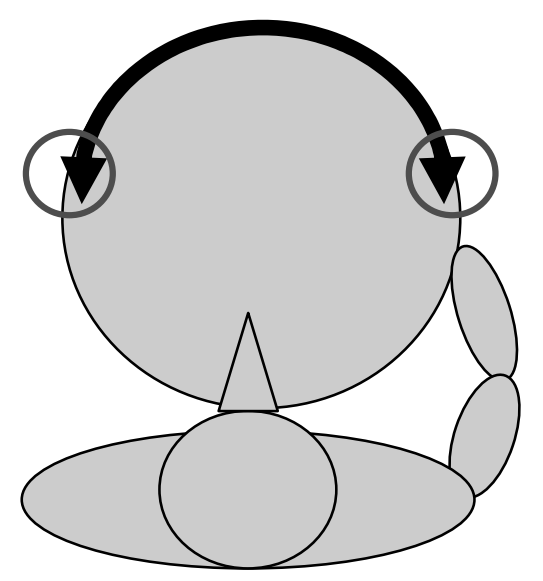

Fig. 4. Mock cooking performance. The subjects gripped the upper end of a rice paddle and stirred at an angle of $180^{\circ}$ at a rate of $10 \mathrm{stirs} / \mathrm{min}$.

ture, relative humidity, globe temperature, and WBGT were measured using the same WBGT meters (WBGT103, Kyoto Electronics Manufacturing Co., Ltd.). After adjusting the dry-bulb temperature at a height of $120 \mathrm{~cm}$, three WBGT meters were set $45 \mathrm{~cm}$ from the center of the cooking plate 90,120 , and $150 \mathrm{~cm}$ from the floor, and the ambient dry-bulb temperature, relative humidity, globe temperature, and WBGT were measured after 2 min. We defined the difference the ambient dry-bulb temperature and globe temperature as radiant heat index. To confirm the output of the stove at the time of the experiment, the time required for heating and the amount of evaporation were compared between the two heat sources.

As physiological responses, body weight, oxygen uptake, heart rate, blood pressure, and body temperature (temperature of the antebrachial skin, abdominal skin, external acoustic meatus, and rectum) were measured. Before and after the experiments, the subjects were weighed using a digital scale (FG-150KBM, A\&D Co., Ltd.), wearing underwear alone. Oxygen uptake was measured using a portable oxygen monitor (K4b2, COSMED Co., Ltd.), and values during the last 1-min period were averaged at 5-min intervals. The heart rate and blood pressure were measured using a portable heart rate/blood pressure monitor (TNGO Co., Ltd.) at 5-min intervals, and double product was calculated based on the measurement values. Body temperature was measured using surface-type probes (Nikkiso YSI Co., Ltd.). To measure temperatures in the antebrachial and abdominal skin, temperature probes were fixed $10 \mathrm{~cm}$ above the right wrist and above the navel, respectively. In addition, a sensor for external acoustic meatus temperature measurement (Nikkiso YSI Co., Ltd.) was inserted into the external acoustic meatus, and a body lumen insertion-type temperature probe (Nikkiso YSI Co., Ltd.) was inserted $10-15 \mathrm{~cm}$ from the anus and fixed for the measurement of rectal temperature. Body temperature values during the last 1-min period were averaged at 5-min intervals. The amount of activity using the IH and gas stoves was estimated using a wrist accelerometer (Actical ITC Co., Ltd.). Concerning the working posture, changes in the trunk inclination angle were evaluated using a 3-axis acceleration sensor (Asakusagiken).

For subjective evaluation of heat and workload by the subjects, a questionnaire was performed at the end of the work. Feelings of heat in the hands, arms, chest, face and abdomen were classified into 5 categories (1: not hot, 2: slightly hot, 3 : hot, 4: considerably hot, 5: intolerably hot). The feeling of work load was also classified into 5 categories (1: not hard, 2: slightly hard, 3: hard, 4: considerably hard, 5: intolerably hard), and the mean value was compared between the two heat sources. To analyze the association between the work environment based on subjective evaluation and physiological responses, the above classifications were re-categorized into two categories (1-3: slightly hot, slightly hard; 4-5: considerably hot, considerably hard), and the two groups were compared. Changes in posture were evaluated using multiple choices (raise an arm, lower an arm, turn the body away, 
turn the face away and bend forward).

\section{Statistical analysis}

The levels of significance of the difference of the environmental and physiological parameters were analyzed using two kinds of examination. To compare the IH and gas stoves, Student's non-paired $t$-test was used. To compare between before and after exposure, Student's paired $t$-test was used.

To compare proportions, the $\chi^{2}$ test or Fisher's exact test was used. Analysis was performed using SPSS.Ver. 15.0 (Japan SPSS, Tokyo). In the two-sided test, $p<0.05$ was considered significant.

\section{Results}

Environment in front of the stove when using IH and gas stoves

As shown in Table 1, after heating to stabilize heat stress before exposure, the ambient dry-bulb temperature, globe temperature, radiant heat index, and WBGT were significantly higher using the gas stove than using the IH stove. At a height of $90 \mathrm{~cm}$, the radiant heat index using the gas stove was about 10 times higher than using the IH stove. After exposure to heat stress for $30 \mathrm{~min}$, the environmental values in front of the IH stove did not change, while ambient dry-bulb temperature, globe temperature, radiant heat index, and WBGT significantly increased in front of the gas stove at each height. Relative humidity $120 \mathrm{~cm}$ and $150 \mathrm{~cm}$ above the gas stove showed significantly decreased heat stress at $30 \mathrm{~min}$, but there was no similar change with the IH cooking stove.

The time required for heating did not significantly differ between the IH stove $(63.5 \pm 10.1 \mathrm{~min})$ and the gas stove $(59.0 \pm 7.0 \mathrm{~min})$, and water evaporation also did not differ between the IH stove $(59.8 \pm 9.5 \%)$ and the gas stove $(57.1 \pm 5.7 \%)$, showing the same output state between the two types of stove.

\section{Physiological responses to heat stress}

As shown in Table 2, physiological responses did not differ between the two heat sources before exposure to heat stress, but significantly increased for both the IH and gas stoves after mock cooking work except for oxygen uptake and external acoustic meatus temperature of the IH stove. After mock cooking work, heart rate, temperature of the antebrachial skin, abdominal and external acoustic meatus, and oxygen uptake significantly differed between the two heat sources. Although oxygen uptake and external acoustic meatus temperature did not differ between the two heat sources before heat stress, because those of the gas stove significantly increased by heat stress, there was a difference between the two heat sources after exposure.

Physical activity intensity estimated using an accelerometer did not differ between the two heat sources. Work posture analysis showed no significant differences between the two heat sources, although the angle of trunk inclination showed a slightly anterior inclination using the $\mathrm{IH}$ stove and slight flexion using the gas stove.

\section{Subjective evaluation of heat stress}

The feeling of heat in the hands, arms, chest, face and abdomen was significantly more marked for the gas stove than for the IH stove at 2.8 vs $4.1,1.9$ vs $3.1,1.8$ vs 2.7 , 1.8 vs 3.7 , and 1.4 vs 2.8 , respectively; however, the feeling of work load did not significantly differ between the two heat sources. In response to heat stress due to the gas stove, the subjects used avoidance postures and actions such as raising their arm (58.3\%), turning their body away $(41.7 \%)$, and turning their face away $(33.3 \%)$. Free descriptions also showed a feeling of heat in the fingers, arms, and face for the gas stove but no such feeling for the IH stove.

Association between work environment and physiological responses according to the feeling of heat

As shown in Table 3, the percentage of subjects who felt "considerably hot" in their abdomen and hands was slightly higher for the gas stove than for the IH stove, but for the face, it was significantly higher. In the groups who felt "considerably hot" in the abdomen, hands and face, there were significant differences in ambient drybulb temperature, globe temperature and body temperature (abdomen and antebrachial skin temperature) between the IH and gas stoves; however, there were no significant differences in ambient dry-bulb temperature at $150 \mathrm{~cm}$ or external acoustic meatus temperature between the IH and gas stoves.

Association between environment in front of the stove and physiological responses according to the feeling of workload

As Table 4 shows, the percentage of subjects who felt that the workload was "considerably hard" was slightly higher for gas stoves than for IH stoves. In the groups who felt that the workload was "considerably hard", there were significant differences in ambient dry-bulb temperature except for $150 \mathrm{~cm}$, globe temperature and body temperature (abdomen, antebrachial skin and external acoustic meatus temperature) between the $\mathrm{IH}$ and gas stoves.

\section{Discussion}

In this study, we found that using the IH stove with 
Table 1. Environment in front of stove before and after exposure to heat stress

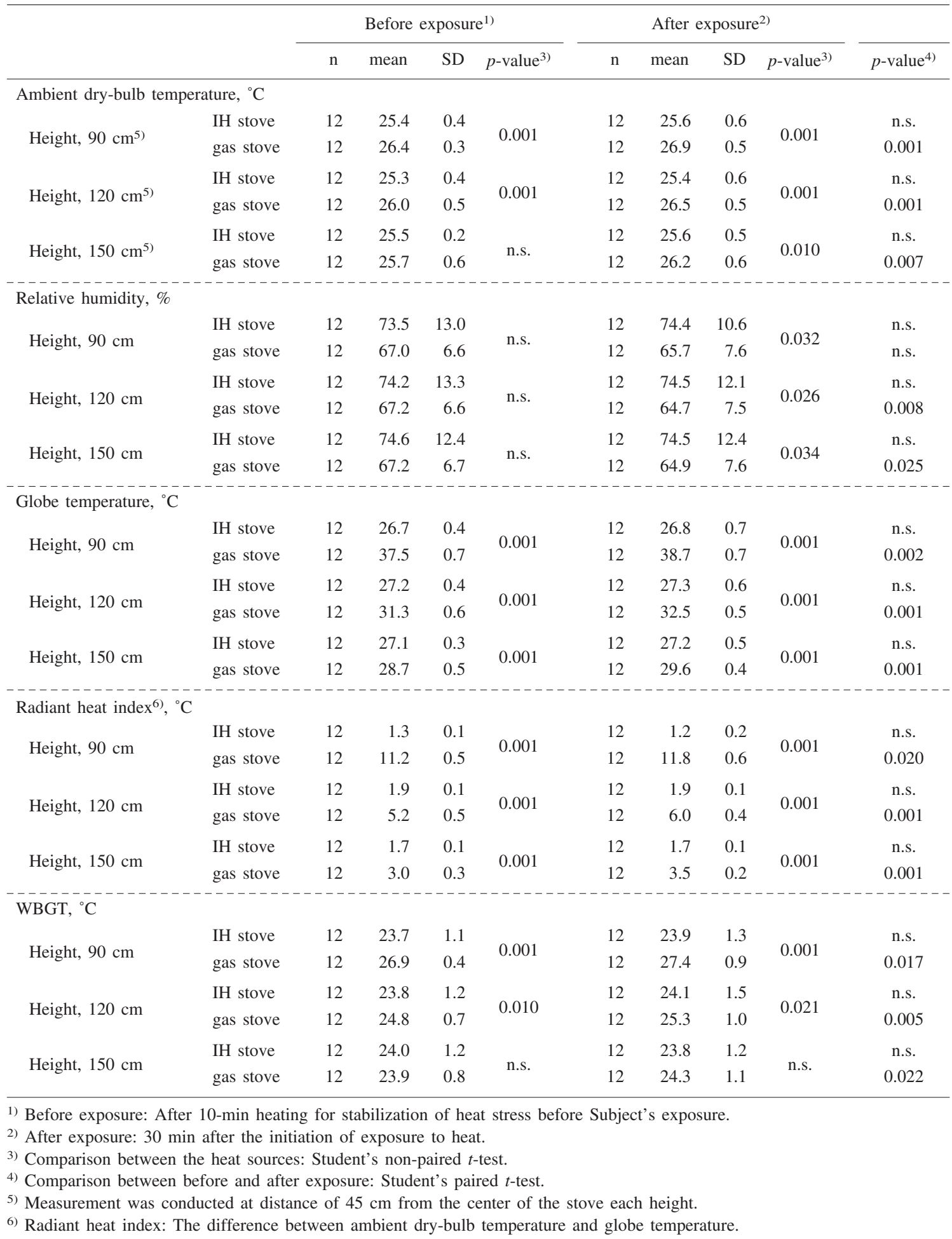

high energy efficiency, heat stress was slight, and no changes were observed in the kitchen environment. Although physiological responses significantly increased for both the IH and gas stoves after mock cooking work, the changes using the IH stove were slight. In addition, subjective evaluation of the feeling of heat and workload showed a close association between these feelings and ambient black globe temperature rather than ambient drybulb temperature.

This study showed the following characteristics. The first was the evaluation of heat stress to which subjects were exposed from multiple aspects by measuring the 
Table 2. Physiological responses before and after exposure to heat stress

\begin{tabular}{|c|c|c|c|c|c|c|c|c|c|c|}
\hline \multirow{2}{*}{ Physiological items } & & \multicolumn{4}{|c|}{ Before exposure $^{1)}$} & \multicolumn{4}{|c|}{ After exposure ${ }^{2)}$} & \multirow[b]{2}{*}{$p$-value ${ }^{4)}$} \\
\hline & & $\mathrm{n}$ & mean & SD & $p$-value ${ }^{3)}$ & $\mathrm{n}$ & mean & SD & $p$-value ${ }^{3)}$ & \\
\hline \multirow[t]{2}{*}{ Weight, kg } & IH stove & 12 & 63.1 & 7.3 & \multirow{2}{*}{ n.s. } & 12 & 63.0 & 7.3 & \multirow{2}{*}{ n.s. } & 0.001 \\
\hline & gas stove & 12 & 62.9 & 7.1 & & 12 & 62.8 & 7.1 & & 0.001 \\
\hline \multirow[t]{2}{*}{ Heart rate, bpm } & IH stove & 11 & 78.6 & 9.8 & \multirow{2}{*}{ n.s. } & 12 & 101.0 & 13.7 & \multirow{2}{*}{ n.s. } & 0.001 \\
\hline & gas stove & 12 & 76.6 & 10.2 & & 12 & 108.8 & 16.9 & & 0.001 \\
\hline \multirow[t]{2}{*}{ Systolic blood pressure, $\mathrm{mmHg}$} & IH stove & 11 & 113.8 & 9.3 & \multirow{2}{*}{ n.s. } & 12 & 124.3 & 12.3 & \multirow{2}{*}{ n.s. } & 0.008 \\
\hline & gas stove & 12 & 115.9 & 11.3 & & 12 & 128.0 & 11.1 & & 0.042 \\
\hline \multirow[t]{2}{*}{ Diastolic blood pressure, $\mathrm{mmHg}$} & IH stove & 11 & 71.5 & 6.3 & \multirow{2}{*}{ n.s. } & 12 & 84.3 & 7.4 & \multirow{2}{*}{ n.s. } & 0.001 \\
\hline & gas stove & 12 & 72.8 & 7.9 & & 12 & 84.8 & 6.6 & & 0.001 \\
\hline \multirow[t]{2}{*}{ Double product, bpm*mmHg } & IH stove & 11 & 8,931 & 1,535 & \multirow{2}{*}{ n.s. } & 12 & 12,505 & 2,201 & \multirow{2}{*}{ n.s. } & 0.001 \\
\hline & gas stove & 12 & 8,864 & 1,643 & & 12 & 13,758 & 1,891 & & 0.001 \\
\hline \multirow[t]{2}{*}{ Oxygen uptake, $\mathrm{ml}^{*} \mathrm{~kg}^{-1} * \mathrm{~min}^{-1} / \mathrm{kg}$} & IH stove & 11 & 4.3 & 0.7 & \multirow{2}{*}{ n.s. } & 11 & 5.4 & 1.0 & \multirow{2}{*}{0.006} & n.s. \\
\hline & gas stove & 12 & 4.6 & 1.4 & & 12 & 6.5 & 0.8 & & 0.001 \\
\hline \multirow[t]{2}{*}{ Amount of activity, METs } & IH stove & 12 & 1.1 & 0.2 & \multirow{2}{*}{ n.s. } & 10 & 1.6 & 0.2 & \multirow{2}{*}{ n.s. } & 0.001 \\
\hline & gas stove & 12 & 1.1 & 0.3 & & 12 & 1.8 & 0.3 & & 0.001 \\
\hline \multirow[t]{2}{*}{ Antebrachial skin temperature, ${ }^{\circ} \mathrm{C}$} & IH stove & 12 & 34.2 & 1.1 & \multirow{2}{*}{ n.s. } & 11 & 36.8 & 0.5 & \multirow{2}{*}{0.001} & 0.001 \\
\hline & gas stove & 12 & 34.1 & 1.1 & & 12 & 39.7 & 1.1 & & 0.001 \\
\hline \multirow[t]{2}{*}{ Abdominal temperature, ${ }^{\circ} \mathrm{C}$} & IH stove & 11 & 34.2 & 0.9 & \multirow{2}{*}{ n.s. } & 11 & 35.2 & 0.7 & \multirow{2}{*}{0.001} & 0.001 \\
\hline & gas stove & 12 & 34.2 & 0.8 & & 12 & 38.4 & 0.8 & & 0.001 \\
\hline \multirow[t]{2}{*}{ External acoustic meatus temperature, ${ }^{\circ} \mathrm{C}$} & IH stove & 12 & 36.3 & 0.3 & & 11 & 36.4 & 0.3 & 001 & n.s. \\
\hline & gas stove & 12 & 36.1 & 0.3 & n.s. & 12 & 37.2 & 0.6 & 0.001 & 0.001 \\
\hline Rectal temperature, ${ }^{\circ} \mathrm{C}$ & IH stove & 12 & 37.1 & 0.3 & $\mathrm{~ns}$ & 11 & 37.2 & 0.3 & $\mathrm{n}$ & 0.009 \\
\hline & gas stove & 12 & 37.1 & 0.3 & 11.5. & 12 & 37.3 & 0.3 & $11 . \mathrm{s}$ & 0.005 \\
\hline
\end{tabular}

1) Before exposure: After 10-min heating for stabilization of heat stress before subjects' exposure.

2) After exposure: $30 \mathrm{~min}$ after the initiation of exposure to heat.

3) Comparison between the heat sources: Student's non-paired $t$-test.

4) Comparison between before and after exposure: Student's paired $t$-test.

Table 3. Association between work envirinment and physiolosical responses according to the subjectives evaluation of hotness

\begin{tabular}{|c|c|c|c|c|c|c|c|c|c|c|c|c|c|}
\hline & & \multirow{2}{*}{\multicolumn{3}{|c|}{$\begin{array}{c}\text { Feeling of hotness } \\
\text { considerably hot }\end{array}$}} & \multicolumn{6}{|c|}{ Ambient ${ }^{1)}$} & \multicolumn{3}{|c|}{ Body } \\
\hline & & & & & \multicolumn{3}{|c|}{ Dry-bulb temperature, ${ }^{\circ} \mathrm{C}$} & \multicolumn{3}{|c|}{ Globe temperature, ${ }^{\circ} \mathrm{C}$} & \multicolumn{3}{|c|}{ Body temperature, ${ }^{\circ} \mathrm{C}$} \\
\hline & & $\mathrm{n}$ & $(\%)$ & $p$-value ${ }^{3)}$ & mean & $\mathrm{SD}$ & $p$-value ${ }^{4)}$ & mean & $\mathrm{SD}$ & $p$-value & mean & $\mathrm{SD}$ & $p$-value \\
\hline \multirow{2}{*}{ Abdomen $^{2)}$} & IH stove & 3 & 22.5 & \multirow{2}{*}{ n.s. } & 25.6 & 0.6 & \multirow{2}{*}{0.006} & 26.9 & 0.6 & \multirow{2}{*}{0.001} & 35.9 & 0.4 & \multirow{2}{*}{0.003} \\
\hline & gas stove & 8 & 66.7 & & 27.0 & 0.6 & & 38.7 & 0.8 & & 38.4 & 1.0 & \\
\hline \multirow{2}{*}{ Hands } & IH stove & 6 & 50.0 & \multirow{2}{*}{ n.s. } & 25.6 & 0.7 & \multirow{2}{*}{0.008} & 27.5 & 0.7 & \multirow{2}{*}{0.001} & 37.1 & 0.5 & \multirow{2}{*}{0.001} \\
\hline & gas stove & 11 & 91.7 & & 26.4 & 0.4 & & 32.5 & 0.5 & & 39.8 & 1.0 & \\
\hline \multirow{2}{*}{ Face } & IH stove & 2 & 16.7 & \multirow{2}{*}{0.001} & 25.7 & 0.2 & \multirow{2}{*}{ n.s. } & 27.4 & 0.2 & \multirow{2}{*}{0.001} & 36.6 & 0.1 & \multirow{2}{*}{ n.s. } \\
\hline & gas stove & 12 & 100.0 & & 26.3 & 0.6 & & 29.7 & 0.5 & & 37.0 & 0.4 & \\
\hline
\end{tabular}

1) Measurement was conducted at each height, concerning feeling of hotness at abdmen, hands and face was at a height of 90 , 120 and $150 \mathrm{~cm}$, respectively.

2) Abdomen: Abdomina temperature, Hand: Antebrachial skin temperature, Face: External acoustic meatus temperature.

3) Fisher's exact test.

4) Comparison between IH and gas stove: Student's non-paired $t$-test.

environment in front of the stove where the subjects stood at multiple measurement heights, and using multiple temperature parameters such as ambient dry-bulb temperature, globe temperature and WBGT. The second was observation of the physiological responses of the subjects to a certain degree of heat stress by an IH or gas stove without allowing avoidance behavior. The third was the evaluation of comfortable kitchen conditions in terms of 
Table 4. Association between work envirinment and physiolosical responses according to the subjectives evaluation of work load

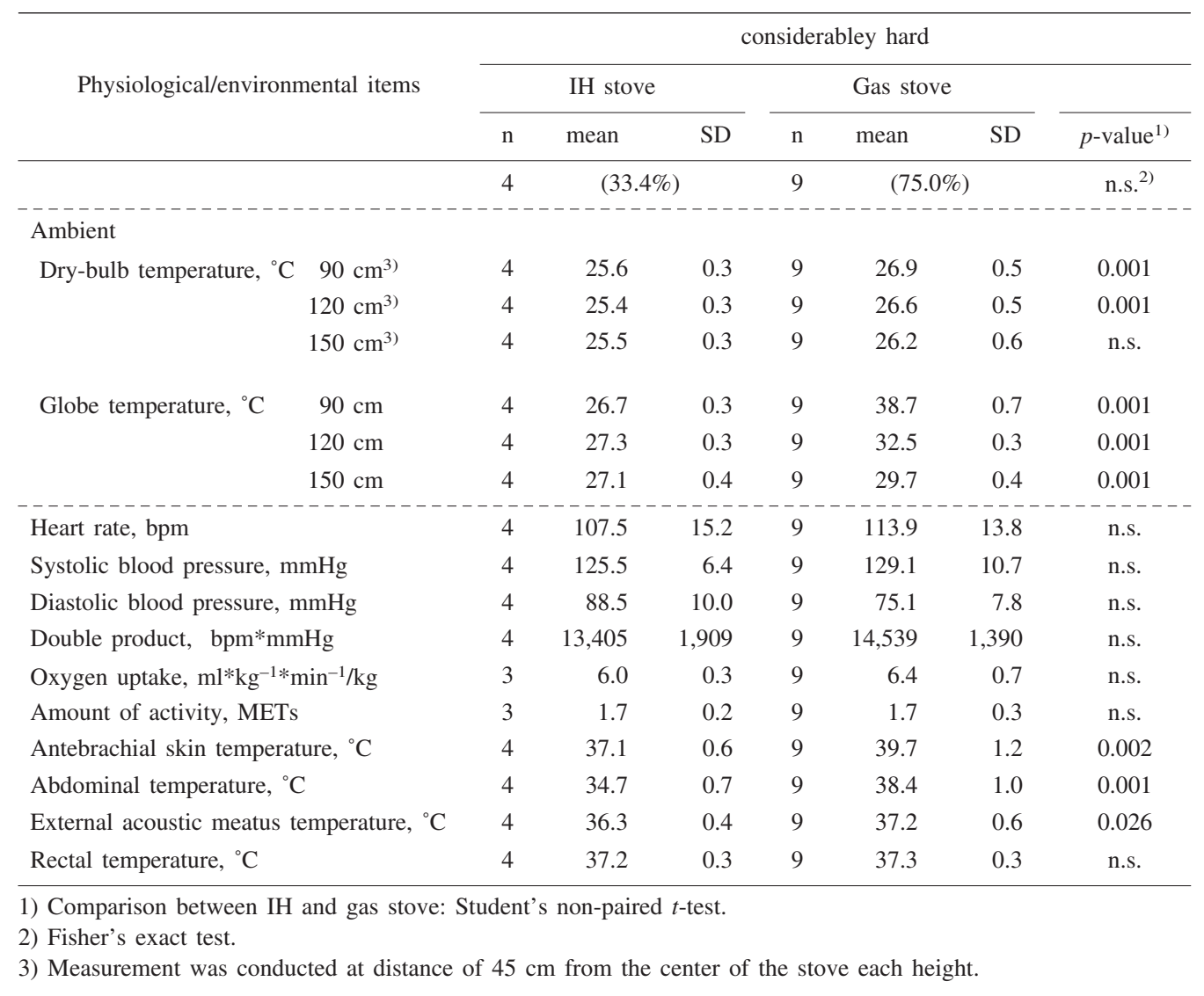

the relationship between the environmental temperature in front of the stove and skin temperature based on subjective evaluation.

We consider that this study has high internal validity based on the following points. First, the ambient temperature for each subject before exposure to heat stress was controlled at $25.0 \pm 0.5^{\circ} \mathrm{C}$ to control the experimental environment. In addition, the output level of the stove was confirmed to be similar in terms of the time required for heating and water evaporation rate. Second, in the measurement of physiological responses, there was no age bias, and subjects not acclimated to heat stress underwent both experiments using the IH or gas stove once each. To exclude the influence of familiarity with the work, training was performed before experiments. The number of subjects in the group performing the experiment using the IH stove first was the same as that in the group performing the experiment using the gas stove first. In addition, to exclude the influence of the experimental initiation time on physiological responses, the two experiments for each subject were initiated at a fixed time of day, and the subjects fasted for $8 \mathrm{~h}$ before experiments. Third, the amount of activity evaluated using an accelerometer and a portable oxygen monitor did not differ between the two heat sources, and the absence of avoidance behavior due to heat stress was confirmed by the absence of a difference in the trunk inclination angle. Thus, since the amount of physical activity did not differ between the two heat sources in this study, and differences in physiological responses are considered to be due to differences in heat stress.

Compared with the gas stove, the IH stove with high energy efficiency showed no changes in ambient dry-bulb temperature, relative humidity, globe temperature, radiant heat index, and WBGT after 30-min heating, suggesting good maintenance of the thermal environment in the kitchen. These findings were consistent with those in previous studies ${ }^{12,13)}$. In this study, 3 types of temperature (ambient dry-bulb temperature, glove temperature and WBGT) were simultaneously measured, and each showed the highest value using the gas stove at a height of $90 \mathrm{~cm}$ after exposure to thermal stress; however, the highest WBGT value was below the permissible high temperature range ${ }^{14)}$, and the ambient dry-bulb temperature also did not exceed $27^{\circ} \mathrm{C}$, indicating a lower temperature than that in kitchens during actual cooking ${ }^{7,8)}$. This may be because the temperature in front of the stove was controlled using an air conditioner, and there was only one 
stove as a source of heat stress. Based on only ambient dry-bulb temperature and WBGT, the experimental environment using either the IH or gas stove was more comfortable than the actual working environment.

The IH stove induced no changes in the work environment due to heat stress. Rectal temperature after heat stress exposure did not differ between the two groups that differed in ambient temperature in front of the stove. Previous studies using a higher dry-bulb temperature, black globe temperature and a longer exposure time than our study have shown rectal temperature similar to in this study ${ }^{15,16)}$. Another study of glass craftsmen showed a heart rate of $90-100$ beats/min when working in the sitting position despite a radiant heat of about $20^{\circ} \mathrm{C}$, suggesting a low load on circulation ${ }^{17)}$. Therefore, considering the intensity of heat stress, mock cooking using only the upper limbs when standing upright, and the exposure time of $30 \mathrm{~min}$ in this study, the workload may not have been so great as to change the heart rate and rectal temperature.

Because this study does not measure detailed physiological endpoints such as blood data, establishing the direct effect is difficult, and is a theme of future research, but a previous study showed that oxygen uptake rises by the activation of peripheral tissues such as skin temperature $^{18)}$. The measurement accuracy of the breathing gas analyzer was not affected in this study.

Concerning the feeling of heat and workload, it is thought that significant difference was not observed because of the small sample size. Concerning the association between the feeling of heat and skin temperature or ambient temperature, the number of subjects who felt that their hands were "considerably hot" was higher than that of subjects who felt that their abdomen or face was "considerably hot". This may be due to the influence of the ascending air current of boiled water on the hands above the pan. Since ambient temperature was measured $45 \mathrm{~cm}$ from the centre of the stove, the actual globe temperatures to which the subjects were exposed may have been higher. The Antebrachial skin temperature was higher than other skin temperatures. Work gloves and an expiratory mask were applied to the hands and face, respectively, to prevent direct exposure to heat stress. On the other hand, the chef's coat used to protect the abdomen is a specific garment for cooking, and its heatdefensive effects may have been marked.

A study on the association between the feeling of workload and heat stress showed an increase in fatigue with an increase in heat stress ${ }^{16)}$. In this study, in the group who felt "considerably hard", ambient black globe temperature was significantly high after exposure, which suggests that exposure to a high temperature range increases the feeling of workload.
The results of this study suggest the following 3 important points to improve the kitchen environment: the use of heating appliances with high energy efficiency producing low heat radiation, because of the association between an increase in globe temperature and an increase in body temperature; the control of globe temperature using an air conditioner because of the marked feeling of total body load at a high black globe temperature; and evaluation of the improvement of the kitchen working environment in terms of not only heat stress but also humidity. This is because of frequent exposure to high humidity in the kitchen due to many types of work using water, and the rectal temperature is high with high humidity ${ }^{19)}$ at the same air temperature, causing marked feelings of workload ${ }^{17)}$, although work leading to increasing humidity was excluded from this study.

The limitations of this study were a small sample size, lack of evaluation of the reliability and validity of the questionnaire used for subjective assessment, and the inclusion of only young men as subjects. Even under the same conditions, the increase in body temperature differs between the aged and young ${ }^{15)}$, and the working temperature range considered to be comfortable differs between males and females ${ }^{20)}$; therefore, it is difficult to generalize the results of studies in young men, ignoring sex and age. In societies with a decrease in the productive population, hopes are placed on the work of women and the elderly. In the future, studies with a greater sample size, including comparisons among age groups and between genders, are necessary. Because both physiological load and subjective awareness of heat and workload were slight in kitchens using the IH stove, which provided a better work environment, the electrified kitchen is thought to be preferable as a comfortable work environment for workers.

\section{References}

1) Maguire K Howard M (2001) A study of the social and physical environment in catering kitchen and the role of the chef in promotion positive health and safety behavior. Int J Environ Health Res 11, 203-17.

2) Oze Y (1984) A hygienic study on health impairment in school lunch cooks (I): Associations between cooking methods and the development of health impairment. Sangyo Igaku 26, 414-24 (in Japanese).

3) Oze Y (1984) A hygienic study on health impairment in school lunch cooks (II): An epidemiological study on various factors involved in the development of health impairment. Sangyo Igaku 26, 425-37 (in Japanese).

4) Sakai K, Watanabe A, Onishi N (1993) Work characteristics of hospital meal cooking and results of a labor burden survey. J Sci Labor 69, 240-52 (in Japanese).

5) Nakata M (1999) Evaluation of school lunch labour in 
Japan by overseas researchers. Sangyo Eiseigaku Zasshi 41, 54-62 (in Japanese).

6) Ito A, Watanabe A, Onishi N (1997) Present status of indoor climates in school lunch kitchens. J Sci Labor 73, 32-3 (in Japanese).

7) Ito A, Watanabe A, Onishi N (1997) Indoor climates of school lunch kitchens using the dry method. J Sci Labor 73, 108-9 (in Japanese).

8) Pekkarinen A (1996) Assessment of health risks in canteen kitchen. Int J Occup Saf Ergon 2, 262-7.

9) Uno U, Tanaka I, Watanabe S, Tabe K (2005) A survey of indoor thermal environments in lunch cooking facilities. 35-40, Bulletin of Aichi Sangyo University (in Japanese).

10) Onishi N, Watanabe A, Sakai K (1998) Work burdens in school lunch work and reduction measures. J Sci Labor 64, 101-34 (in Japanese).

11) Engels JA (1994) Physical work load and its assessment among the nursing staff in Nursing Homes. J Occup Med 36, 338-45.

12) Komine H, Ishiguro K, Umenushi $Y$, Matsuda $T$ (1990) Experimental study on thermal environment and air pollution in kitchen installed with electric cooking equipments for occupational use. Part 1. Influence of types of cooking equipments, electromagnetic cooking ranges and electric heating ranges. 579-80, Summaries of Technical Papers of Annual Meeting, Architectural Institute of Japan (in Japanese).

13) Ishiguro K, Komine H, Matsuda T, Umenush Y (1992)
Experimental study on thermal environment and air pollution in kitchen installed with electric cooking equipments for occupational use. Part 2, Results of experiments. 869-70, Summaries of Technical Papers of Annual Meeting, Architectural Institute of Japan (in Japanese).

14) Japan Society of Occupational Health (2004) Recommendation of permissible concentration. Sangyo Eiseigaku Zasshi 46, 124-154 (in Japanese).

15) Smolander J, Korhonen O, Ilarinen R (1990) Response of young and older men during prolonged exercise in dry and humid heat. Eur J Appl Physiol Occup Physiol 61, 413-8.

16) Chen ML, Chen CJ, Yeh JW, Huang JW, Mao IF (2003) Heat stress evaluation and worker fatigue in a steel plant. AIHA J 64, 352-9.

17) Rastogi SK, Gupta BN, Husain T (1992) Wet-bulb globe temperature index: a predictor of physiological strain in hot environment. Occup Med 42, 93-7.

18) Rodahl K (2003) Occupational health conditions in extreme environments. Ann Occup Hyg 47, 241-52.

19) Nag PK, Bandyopadhyay P, Ashtekar SP, Kothari D, Desai H, Nag A (2002) Human work capacity under combined stress of work and heat. Hum Ergon 25, 105-13.

20) Beshir MY, Ramsey JD (1981) Comparison between male and female subjective estimates of thermal effects and sensations. Appl Ergon 12, 29-33. 